\title{
AIR FLOW PATTERNS IN AN INDUSTRIAL MILK POWDER SPRAY DRYER
}

\author{
John R. GABITES ${ }^{1}$, John ABRAHAMSON ${ }^{1}$ and James A. WINCHESTER ${ }^{2}$ \\ ${ }^{1}$ Department of Chemical and Process Engineering, University of Canterbury, Christchurch, NEW ZEALAND \\ ${ }^{2}$ Heat Transfer \& Drying Team, Clandeboye Site, Fonterra Co-operative Group Ltd, Temuka, NEW ZEALAND
}

\begin{abstract}
The air flow patterns in an industrial milk powder spray dryer were investigated. Isothermal three-dimensional transient simulations were carried out using the commercial CFD code CFX10.0. The Shear Stress Transport (SST) turbulence model was implemented to model the effects of turbulence.

These simulations differ from previously published studies of spray dryer air flows in that they include features found in industrial scale plant. First, they include a second inlet air stream through the internal fluid bed at the bottom of the drying chamber. Second, the two outlet ducts are located near the top rather than the bottom of the dryer, which has been the case in most previous studies.

It was found that the main air jet oscillated and precessed about the central axis. In turn, the recirculation zones between the main jet and the chamber walls fluctuated in size relative to the movement of the jet.

Validation was achieved by observing the oscillation of the main air jet of a large dryer visualised by tell-tail tufts attached to a central pole.
\end{abstract}

\section{INTRODUCTION}

Spray drying is the transformation of a feed from a fluid state into a dried form by spraying the feed into a hot drying medium (Masters, 1972). This drying technique is used in a number of process industries for the production of foodstuffs, detergents, pharmaceuticals and cosmetics (Masters, 1972).

Fonterra Co-operative Group Ltd, the world's largest exporter of milk products, operates some 40 spray dryers across 25 manufacturing sites within New Zealand. One such plant is the world's largest milk powder plant, situated on the Clandeboye site near Temuka in the South Island.

Computational Fluid Dynamics (CFD) methods have become a powerful tool due to computational advances, and have been used to study spray dryers (Nijdam et al., 2004). These CFD techniques have been used to compare the performance of rotary disc and pressure nozzle atomisation (Huang et al., 2006), assess chamber design alternatives (Huang et al., 2003, Southwell et al., 2001) and predict drying performance ( $\mathrm{Li}$ and Zbicinski, 2005, Southwell et al., 1999).

Air flow patterns in spray dryers have been the subject of numerous experimental and CFD studies. (Langrish et al., 1992) give a review of flow visualisations. Numerous CFD simulations on spray dryers have been published (Fletcher et al., 2003, Guo et al., 2003, Harvie et al., 2002, Kieviet et al., 1997, Langrish, 1993, Langrish et al., 2004,
LeBarbier et al., 2001, Oakley and Bahu, 1990, Stafford et al., 1996, Straatsma et al., 1999).

Stafford et al. (1996) used particle image velocimetry (PIV) to measure the velocity field in a small spray dryer with pressure nozzle atomisation. They observed for the case of no inlet swirl, an off centre jet and no symmetrical recirculation zone. The left hand and right hand wall flows were seen to flow upwards and downwards respectively. This flow pattern was attributed to maldistribution of the inlet air.

Kieviet et al. (1997) compared 2D simulations with experimental measurements of a pilot scale spray dryer (height $0.373 \mathrm{~m}$ ) without atomisation. The results for the no inlet swirl case indicated a fast flowing core that diverged as it progressed into the chamber. Measurements of sensible mean velocities in the recirculation zones near the walls were not possible due to the unstable flow. These instabilities were attributed to a wiggling core.

Guo et al. (2003) performed transient 3D simulations with CFX 4.4 on a sudden expansion/sudden contraction, as well as a laboratory scale spray dryer (height $2.8 \mathrm{~m}$ ). They found that with no inlet swirl to the spray dryer, the flow was unstable and a periodic oscillation resulted. The downward flowing jet moved in a quasi flapping pattern with a period of $4.6 \mathrm{~s}$. They concluded the movement of the central jet was due to pressure fluctuations in the large recirculation zones between the jet and the walls, and that future simulations had to be $3 \mathrm{D}$ to fully capture these effects.

Langrish et al. (2004) simulated the effects of inlet swirl on the flow patterns in a pilot-scale spray dryer (height $1.61 \mathrm{~m}$ ). For the case of no inlet swirl, these authors found that the base of the central jet moved or precessed slightly around the axis with time, indicating that steady state simulations of spray dryers are of limited validity. They modelled the effects of turbulence with the shear stress transport (SST) model. The SST model is a statistical turbulence model that solves the $\mathrm{k}-\omega$ model at the wall and solves the k- $\varepsilon$ model in the bulk. A blending function is employed in CFX 10.0 to create a smooth transition between the two (ANSYS, 2005a). This model is one of the most effective models to overcome the problems of the standard k- $\varepsilon$ model with non-equilibrium boundary conditions (ANSYS, 2005b).

The majority of spray dryer studies have been conducted on laboratory or pilot scale equipment. This allows for easier measurement of flow properties using experimental techniques such as hot wire anemometry and Laser Doppler Anemometry and hence, validation of CFD simulations.

These studies provide valuable information about the mechanisms within a spray dryer, but they do not truly represent the industrial situation. Modern spray dryers 
(Figure 1) are two stage dryers where internal fluidised beds at the base of the chamber provide the second stage of drying. This allows for lower outlet air temperatures because of the evaporation occurring in the fluid bed, thus improving dryer efficiency and making the operation even more suitable for drying heat sensitive materials (Westergaard, 2003).

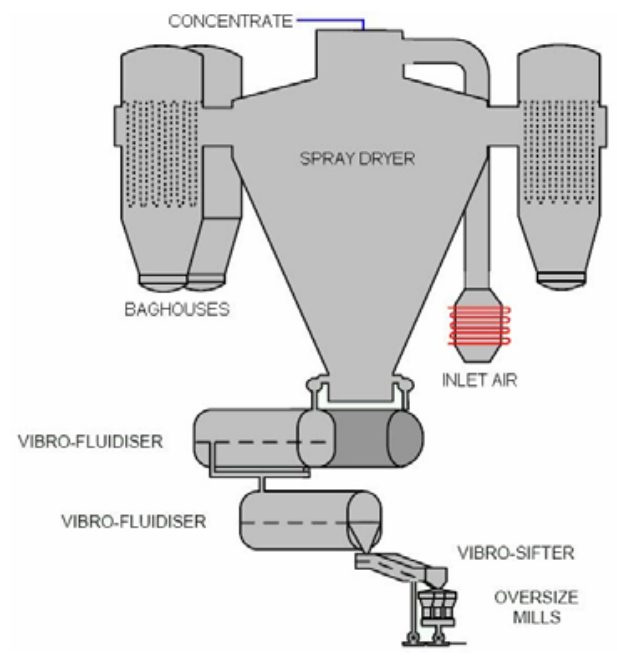

Figure 1: Schematic of modern milk powder plant

The difficulty with experiments and therefore validation on industrial dryers is their large sizes, the massive costs involved and the hostile environment for flow, temperature and humidity measurements (Huang et al., 2006). Also, industrial scale simulations that include transient particle tracking, hindered drying and wall deposition are extremely expensive computationally (Fletcher et al., 2003).

Straatsma et al. (1999) developed a 2D drying simulation model to investigate two industrial spray dryers (heights 14 and $17 \mathrm{~m}$ ) used for milk powder production. The air outlets in both cases were at the top of the chamber but no internal fluid bed was included. The flow field predicted for the larger of the two chambers that used nozzle atomisers was a fast flowing core with large recirculation zones between the central jet and the walls. These simulations were steady state and included no validation, so no transient behaviour was reported.

Fletcher et al. (2003) conducted a full transient simulation with particle tracking, hindered drying and wall deposition for an industrial spray dryer (height $30 \mathrm{~m}$ ). A deflected main inflow jet precessed slowly with time around the central axis. The offset outlet pipe at the base of the chamber caused the central jet to be significantly off the dryer axis. However, like the simulations of Straatsma et al. (1999), there was no internal fluid bed flow nor any validation attempted.

Also, in an increasing number of modern spray dryers, the outlet air passes through ducts located near the top of the chamber rather than through a single outlet near the bottom of the chamber. The presence of the outlet air ducts at the top of the chamber means dry fine powder is recirculated to the top of the chamber to interact with the atomiser cloud, thus increasing agglomeration. This mechanism is known as spontaneous secondary agglomeration (Westergaard, 2003).

This paper examines the flow patterns in an industrial spray dryer used for milk powder production. The aim was to determine the transient behaviour of the flow field where a fluid bed air flow was included, and validate the simulations against data collected from the industrial scale.

\section{MODEL DESCRIPTION}

\section{Geometry}

The industrial chamber geometry used (Figure 2) is a modified conical type. Due to confidentiality the actual dimensions cannot be reported, but it should be noted that they are larger than those of Straatsma et al. (1999).

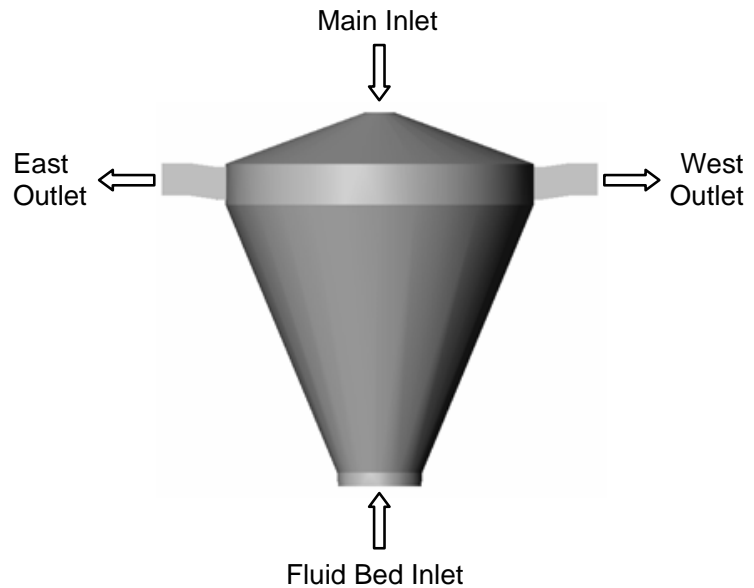

Figure 2: Industrial spray dryer geometry used for simulations and experimental work

The main airflow enters the chamber between the pressure nozzle lances and external recycle fines return holes in the circular flat plate at the top of the chamber. This flow has passed through an air disperser designed to ensure a uniform flow pattern, so it can be assumed there is no swirl in the inlet. The fluid bed air enters a plenum chamber then flows up through the perforated plate, inducing some swirl, which is the base of the chamber in Figure 2. Both air streams are drawn out through the two identical ducts located near the top of the chamber by extractor fans, and hence the chamber and ducts are under vacuum.

\section{Boundary Conditions}

The air flow in this simulation was assumed to be incompressible and isothermal at $25^{\circ} \mathrm{C}$.

The inlet velocity was set at $17.5 \mathrm{~m} / \mathrm{s}$ with a turbulent intensity of $3.7 \%$ and a turbulent length scale based on the inlet diameter. This inlet turbulence approach is identical to that of a number of studies (Guo et al., 2003, Harvie et al., 2001, Harvie et al., 2002, LeBarbier et al., 2001).

The fluid bed air inlet is modelled as a circular inlet where the velocity is set at $0.77 \mathrm{~m} / \mathrm{s}$ with no swirl. Again a turbulence intensity of $3.7 \%$ was used with a turbulent length scale based on the fluid bed inlet diameter.

Average static pressures of - $60 \mathrm{~Pa}$ were specified in the two outlet air ducts. The chamber walls were treated with the default CFX 10.0 boundary conditions of no slip, with smooth, adiabatic walls. 


\section{Simulation Procedure}

3D simulations were carried out using the commercial CFD package CFX 10.0. The transient Reynolds Averaged Navier-Stokes equations and the Shear Stress Transport (SST) turbulence equation were used to model the effects of turbulence. Second order discretization schemes were used in both time and space to convert the partial differential equations into a system of algebraic equations.

Using this scheme, convergence was not possible for steady state simulations, indicating, as expected, that the simulations needed to be run in transient mode. The unconverged steady state results were used as an initial guess for the transient simulations.

A convergence criterion of a maximum residual of $1 \mathrm{x}$ $10^{-4}$ was used to terminate the coefficient iterations. Usually only two or three iterations at each time step were required when using a time step of $0.01 \mathrm{~s}$. A total simulation time of $40 \mathrm{~s}$ was specified.

An unstructured mesh was used with inflation layers at the walls, to ensure boundary layer effects were properly captured. The mesh density was increased in the region around the main inlet air stream at the top of the chamber and in the outlet air ducts, where large gradients exist.

To check that the solutions obtained were independent of the mesh, the simulations were repeated using mesh consisting of approximately 270000, 326000 and 354000 nodes. The results from each compared favourably and the simulation was deduced to be mesh independent. The mesh with 326,000 nodes was used for the results presented here.

Velocity components in the $\mathrm{x}, \mathrm{y}$ and $\mathrm{z}$ directions, along with the pressure at four fixed points, were recorded for each time step.

\section{EXPERIMENTAL}

The spray dryer was run on ambient air with a main inlet air flow giving an inlet velocity of $19.1 \mathrm{~m} / \mathrm{s}$ and a fluid bed flow that gave a measured velocity of $0.77 \mathrm{~m} / \mathrm{s}$. The main inlet velocity was slightly higher than that simulated.

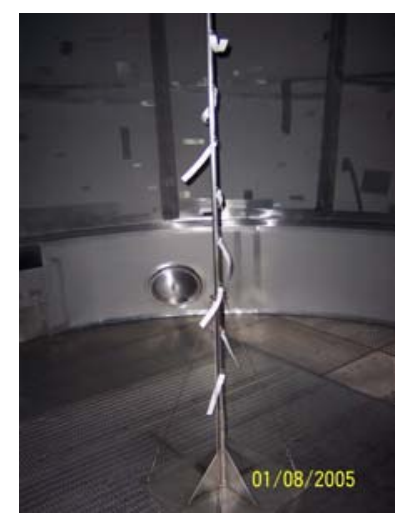

Figure 3: Tell tail pole located at centre of dryer fluid bed for observing the movement of the main air jet

The period of oscillation of the main air jet was measured using a tell tail pole (Figure 3). The $3 \mathrm{~m}$ pole placed in the centre of the fluid bed, had fabric tufts placed every $200 \mathrm{~mm}$ up the pole and enabled the motion of the jet to be recorded with a video camera (Sony Mini DV Digital Handycam).

\section{RESULTS}

\section{Simulation}

The major flow feature in the drying chamber is the main axial jet entering the top of the chamber. It diverges slightly, slows as it moves further into the dryer and moves about the central axis with time. There is very little flow normal to the dryer axis, with the axial flows dominating.

The low velocity fluid bed air flows up and creates a stagnation point with the main jet approximately $1 \mathrm{~m}$ above the fluid bed. At this point, the flow is radial, but the flow switches from being split to both walls or all favouring one wall or the other due to the movement of the main jet. The position of the stagnation point moves up and down.

Between the main jet and the walls of the chamber, slow recirculation zones are evident. The sizes of these zones swell and compress causing the main jet to also change in size and move about the central axis. This movement of the jet also increases the velocities near the walls; they increase when the jet is on the opposite side and decrease when it moves close to the wall.

The movement of the main jet can be observed through a series of 3D snapshots. The three snapshots of the jet behaviour in Figure 4 are taken 30, 33 and 36 seconds from the start of the simulation. It can be seen that the jet flaps through the central axis of the dryer and not along any distinct plane.

At $33 \mathrm{~s}$, the main jet is seen to move close to the chamber walls. Thus, it is likely that wet droplets entrained in the main air jet will impact on the wall. If these droplets adhere, they can brown and therefore have a negative impact on product quality as well as becoming a fire and explosion risk.

Interestingly, the vector plots in Figure 4 show some flow from the main inlet travels straight to the outlets along the roof of the chamber. This implies that some particles will have much shorter residence times compared to those that flow to the bottom of the chamber or become caught in the recirculation zones, and therefore will have higher moisture contents. Smaller particles from the atomiser are more likely to be entrained in this air flow and thus exit the drying chamber through one of the two outlets. Future particle tracking simulations aim to deduce if this is so.

The air velocities in the outlet ducts are high. As expected, they are much higher in magnitude than the majority of velocities in the chamber, as these ducts, are quite small in cross section area when compared to the cross sectional area of the chamber. These velocities are seen to surge slightly with the movement of the main jet in the chamber. This could possibly be the explanation of what is termed by industrial operators as 'breathing'.

Langrish et al. (2004) found from experimental and simulations on a pilot scale spray dryer that for the case of no inlet swirl, no distinct frequency. From simulations of an industrial scale spray dryer, Fletcher et al. (2003) found the main jet had a frequency of approximately $1 \mathrm{~Hz}$, but stated the presence of higher frequencies were evident.

Therefore, it is to be expected that no apparent frequency exists, which the simulations have shown. The presence of a fluid bed flow could add to the instability of the flow field, as no fluid bed flow was modelled by Langrish et al. (2004) or Fletcher et al. (2003). 

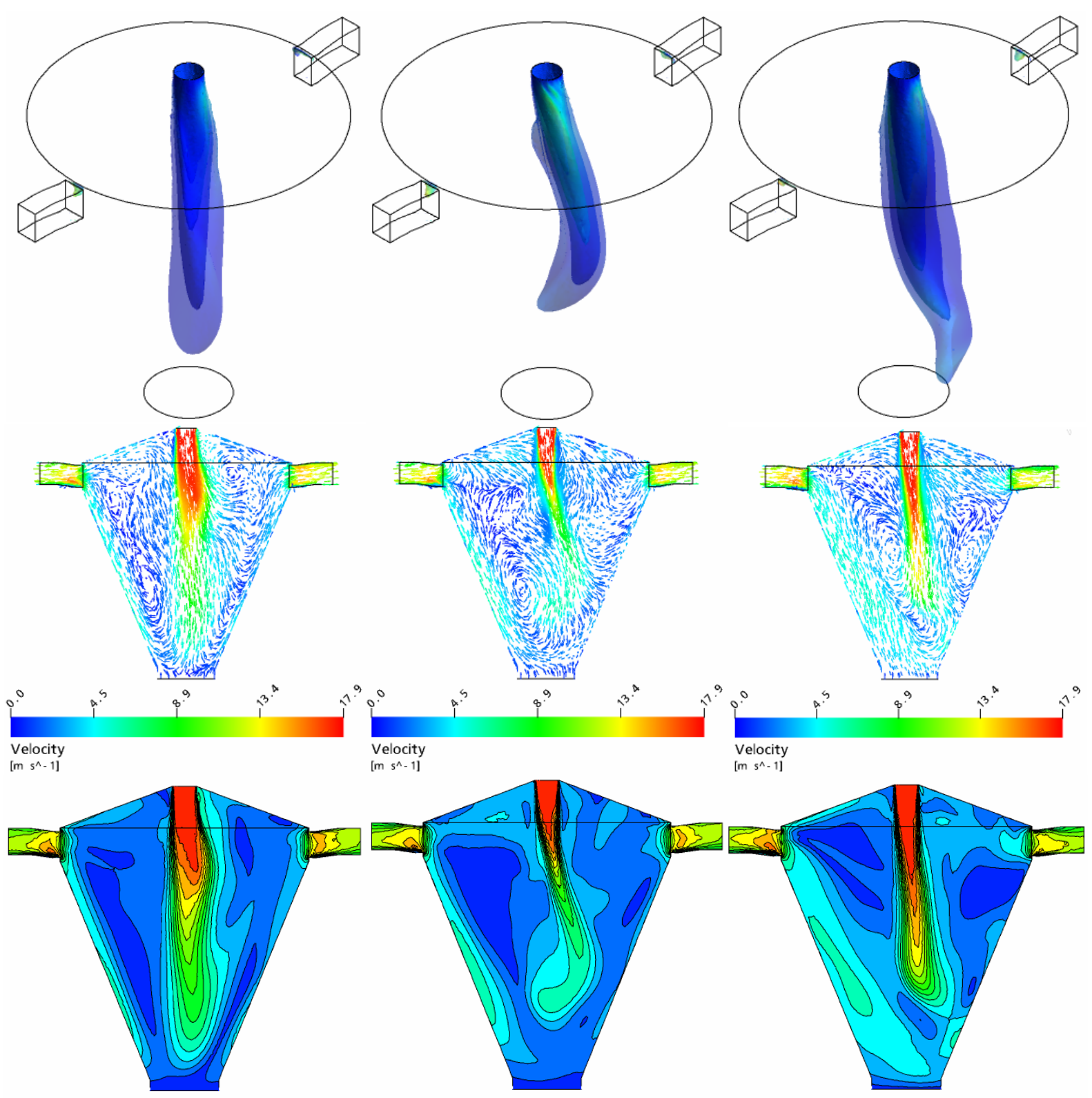

$m s^{\wedge}-11$

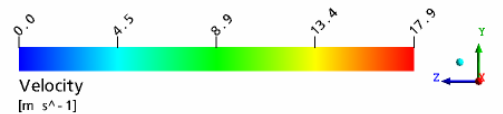

$30 \mathrm{~s}$

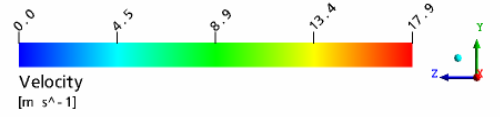

$33 s$

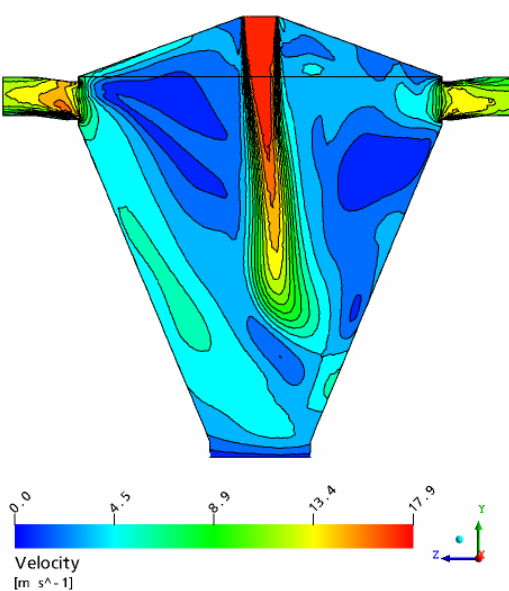

$36 s$

Figure 4: Snapshots of 3D axial velocity contour of the main jet, 2D velocity vector and 2D velocity contour plots through the central plane of the dryer axis 30, 33 and 36 seconds from the start of the simulation

\section{Experimental}

The tell-tail tuft observations showed a reasonably consistent behaviour: the tufts would flap in one direction, the flapping would die away as the tails pointed toward the fluid bed at the bottom of the chamber, and then flap again but in the opposite direction. The period of oscillation was estimated by determining the time between directional changes of the tails. The estimated periods ranged from approximately $2 \mathrm{~s}$ to around $10 \mathrm{~s}$.

\section{CONCLUSIONS}

The air flow patterns in an industrial spray dryer used for milk powder production have been modelled using the transient Reynolds Averaged Navier-Stokes equations with the SST turbulence model. This is possibly the first published work to include the influence of a spray dryer's internal fluid bed airflow on the flow patterns in spray dryers. Also, the geometry in this work has outlet air ducts near the top rather than the bottom of the drying chamber.

The results showed that the main axial jet dominates the flow field and moves about the central axis of the dryer with time. Recirculation zones were observed between this jet and the dryer walls that change in size relative to the motion of the main jet. No apparent distinct frequency is observed which agrees well with the literature and experimental measurements made on the industrial scale dryer. 
Although the fluid bed flow had a small impact on the total flow field, it is likely to have destabilised the flow field.

Visualisation of the main jet movement was achieved by running the industrial dryer on ambient air and measuring the main jet period with tell tails in the dryer. These observations confirmed the transient nature of the main jet and that no apparent distinct frequency exists, as the tuft movements had periods ranging from approximately $2 \mathrm{~s}$ to $10 \mathrm{~s}$.

These findings reiterate the conclusions of previous authors that transient, 3D simulations are required to fully capture the flow features of spray dryers.

\section{ACKNOWLEDGEMENTS}

The authors wish to thank $\mathrm{Mr}$ Nathan Bushnell (Department of Chemical and Process Engineering, University of Canterbury) for his academic support and Fonterra Clandeboye Powder plant staff for their industrial support. This work has received funding from the Foundation for Research Science and Technology (FRST) and Fonterra Co-operative Group Ltd.

\section{REFERENCES}

ANSYS (2005a) CFX 10.0 Manual, Canonsburg.

ANSYS (2005b) Innovative turbulence modelling: SST model in ANSYS CFX. Canonsburg.

FLETCHER, D. F., GUO, B., HARVIE, D. J. E., LANGRISH, T. A. G., NIJDAM, J. J. \& WILLIAMS, J. (2003) What is important in the simulation of spray dryer performance and how do current CFD models perform. Third International Conference on CFD in the Minerals and Process Industries. Melbourne.

GUO, B., LANGRISH, T. A. G. \& FLETCHER, D. F. (2003) Simulation of gas flow instability in a spray dryer. Trans IChemE, Part A, Chem Eng Res Des, 81, 631-638.

HARVIE, D. J. E., LANGRISH, T. A. G. \& FLETCHER, D. F. (2001) Numerical simulations of gas flow patterns within a tall-from spray dryer. Trans IChemE, Part A, Chem Eng Res Des, 79, 235-248.

HARVIE, D. J. E., LANGRISH, T. A. G. \& FLETCHER, D. F. (2002) A computational fluid dynamics study of a tall-from spray dryer. Trans IChemE, Part C, Food Bioprod Process, 80, 163-175.

HUANG, L., KUMAR, K. \& MUJUMDAR, A. S. (2003) Use of computational fluid dynamics to evaluate alternative spray dryer chamber configurations. Drying Technol, 21, 385-412.

HUANG, L., KUMAR, K. \& MUJUMDAR, A. S. (2006) A comparative study of a spray dryer with rotary disc atomizer and pressure nozzle using computational fluid dynamic simulations. Chem. Eng. Process, 45, 461470.

KIEVIET, F. G., VAN RAAIJ, J., DE MOOR, P. P. E. A. \& KERKHOF, P. J. A. M. (1997) Measurement and modelling of the air low pattern in a pilot-plant spray dryer. Trans IChemE, Part A, Chem Eng Res Des, 75, 321-328.

LANGRISH, T. A. G. (1993) The flow patterns of gas and particles in spray dryers. Chem Eng Aust, 18, 16-20.
LANGRISH, T. A. G., KEEY, R. B. \& HUTCHINSON, C. A. (1992) Flow visualization in a spray dryer fitted with a vaned-wheel atomizer. Trans IChemE, Part A, Chem Eng Res Des, 70, 385-394.

LANGRISH, T. A. G., WILLIAMS, J. \& FLETCHER, D. F. (2004) Simulation of the effects of inlet swirl on gas flow patterns in a pilot-scale spray dryer. Trans IChemE, Part A, Chem Eng Res Des, 82, 821-833.

LEBARBIER, C., KOCKEL, T. K., FLETCHER, D. F. \& LANGRISH, T. A. G. (2001) Experimental measurement and numerical simulation of the effect of swirl on flow stability in spray dryers. Trans IChemE, Part A, Chem Eng Res Des, 79, 260-268.

LI, X. \& ZBICINSKI, I. (2005) A sensitivity study on CFD modelling of cocurrent spray-drying process. Drying Technol, 23, 1681-1691.

MASTERS, K. (1972) Spray drying - an Introduction to principles, operating practises and applications, London, Leonard Hill Books.

NIJDAM, J. J., GUO, B., FLETCHER, D. F. \& LANGRISH, T. A. G. (2004) Challenges of simulating droplet coalescence within a spray. Drying Technol, 22, 1463-1488.

OAKLEY, D. E. \& BAHU, R. E. (1990) Computational modelling of spray dryers. European Symposium on Computer Aided Process Engineering - 2. Toulouse.

SOUTHWELL, D. B., LANGRISH, T. A. G. \& FLETCHER, D. F. (1999) Process intensification in spray dryers by turbulence enhancement. Trans IChemE, Part A, Chem Eng Res Des, 77, 189-205.

SOUTHWELL, D. B., LANGRISH, T. A. G. \& FLETCHER, D. F. (2001) Use of computational fluid dynamics techniques to assess design alternatives for the plenum chamber of a small spray dryer. Drying Technol, 19, 257-268.

STAFFORD, R. A., FAUROUX, O. \& GLASS, D. H. (1996) Flow visualisation and instantaneous velocity measurements of spray dryer gas and spray flows using particle image velocimetry. 10th International Drying Symposium. Krakow.

STRAATSMA, J., VAN HOUWELINGEN, G., STEENBERGEN, A. E. \& DE JONG, P. (1999) Spray drying of food products: 1. simulation model. J Food Eng, 42, 67-72.

WESTERGAARD, V. (2003) Milk powder technology, Gladsaxevej, GEA Niro A/S. 